\title{
Fructus sophorae attenuates secretion of proinflammatory mediators and cytokines through the modulation of NF-KB and MAPK signaling pathways in LPS-stimulated RAW 264.7 macrophages
}

\author{
Yung Hyun Choi ${ }^{1,2}$ and Hye-Joo Kang ${ }^{1,2}$ \\ ${ }^{1}$ Department of Biochemistry, Dongeui University College of Korean Medicine, 52-57, Yangjeong-ro, Busanjin, Busan $614-$ \\ 052, Republic of Korea \\ 2 Anti-Aging Research Center and Blue-Bio Industry RIC, Dongeui University, 176 Eomgwangno Busanjin-gu, Busan 614- \\ 714, Republic of Korea
}

\begin{abstract}
This study investigated the inhibitory effects and underlying mechanisms of Fructus sophorae, the dried ripe fruit of Styphnolobium japonicum (L.) Schott, on the production of proinflammatory molecules in lipopolysaccharide (LPS)-stimulated RAW 264.7 macrophages. The results indicated that pretreatment with noncytotoxic concentrations of Fructus sophorae extract (FSE) significantly inhibited the release of the proinflammatory mediators nitric oxide $(\mathrm{NO})$ and prostaglandin $\mathrm{E}_{2}$, which were associated with the downregulation of both mRNA and protein for inducible NO synthase and cyclooxygenase-2, respectively, in LPS-challenged RAW 264.7 cells. FSE also blocked the LPS-induced expression of the proinflammatory cytokines interleukin (IL)- 6 and IL-1 $\beta$. Furthermore, the results showed that FSE efficiently attenuated the LPS-induced nuclear translocation of nuclear factor-kappa B $(\mathrm{NF}-\kappa \mathrm{B})$ and phosphorylation of the mitogen-activated protein kinases (MAPKs) extracellular signal-regulated kinase (ERK) and c-Jun N-terminal kinase (JNK) but not p38 MAPK. These results suggest that FSE exhibits anti-inflammatory activity by inhibiting proinflammatory mediators and cytokines through the inactivation of NF- $\kappa \mathrm{B}, \mathrm{ERK}$ and JNK, and it may offer therapeutic potential for treating inflammatory diseases accompanied with macrophage activation.
\end{abstract}

Key words: Fructus sophorae - Anti-inflammation - NF- $\kappa B-$ MAPKs

\section{Introduction}

Inflammation is an important host response to infection or tissue injury. It results in the activation of various immune cells and leads to the restoration of tissue structure and function. Many inflammatory diseases, such as arthritis, inflammatory bowel diseases, and asthma, may occur if the regulation of the inflammatory response is disrupted (Laveti et al. 2013; Kotas and Medzhitov 2015).

Among the several types of immune cells, macrophages are essential in releasing proinflammatory molecules in response to various harmful stimuli. When macrophages

Correspondence to: Yung Hyun Choi, Department of Biochemistry, Dongeui University College of Korean Medicine, 52-57, Yangjeongro, Busanjin, Busan 614-052, Republic of Korea

E-mail: choiyh@deu.ac.kr are activated by inflammatory stimuli, they release assorted proinflammatory factors necessary for the progression of numerous chronic inflammatory diseases. A common stimulus is lipopolysaccharide (LPS), an endotoxin from gram-negative bacteria. LPS binds to the toll-like receptor 4 (TLR4) expressed on macrophages (Leon et al. 2008; Drexler and Foxwell 2010). This complex triggers a serial of signal transduction events leading to the activation of nuclear factor $-\kappa B(N F-\kappa B)$ and mitogen-activated protein kinases (MAPKs) signaling pathways (Verstrepen et al. 2008; Lucas and Maes 2013). The activated macrophages secrete proinflammatory mediators, such as nitric oxide (NO) and prostaglandin $\mathrm{E}_{2}\left(\mathrm{PGE}_{2}\right)$, which are synthesized by inducible NO synthase (iNOS) and cyclooxygenase-2 (COX-2), respectively (Tsatsanis et al. 2006; Kalinski 2012). They also produce inflammatory cytokines, such as tumor necrosis factor- $\alpha$ (TNF- $\alpha$ ), interleukin (IL)-6, and IL-1 $\beta$ (Keystone 
and Ware 2010; Lane and Lachmann 2011; Lee et al. 2015; Rossi et al. 2015). Therefore, the inhibition of macrophage activation has been suggested as a potential therapeutic goal in relieving the progression of inflammatory diseases.

Under normal conditions, the p50 and p65 subunits of the NF- $\kappa \mathrm{B}$ dimmers are attached to the suppressor protein inhibitor of NF- $\kappa \mathrm{B}(\mathrm{I} \kappa \mathrm{B})$ in the cytoplasm. The activation of NF- $\kappa$ B occurs via phosphorylation through the activation of MAPKs and the degradation of $I \kappa B$ bound to NF- $\kappa \mathrm{B}$. This results in the translocation of NF- $\kappa \mathrm{B}$ from the cytoplasm to the nucleus to promote the expression of various proinflammatory genes, including iNOS, COX-2, and cytokines (Lan et al. 2012; Hayden and Ghosh 2014). The MAPKs, such as extracellular signal-regulated kinase (ERK), c-Jun N-terminal kinase (JNK), and p38 MAPK, are signaling molecules that also play important roles in relaying inflammatory information from the extracellular space to the cytoplasm and nucleus to modulate inflammatory responses (Broom et al. 2009; Patterson et al. 2014). The activation of MAPKs by phosphorylation is a critical step in the production of proinflammatory molecules in activated macrophages. Moreover, previous studies have shown that MAPKs can be activated by TLR4, leading to the activation of the nuclear translocation of NF- $\mathrm{BB}$ and, finally, the initiation of proinflammatory responses (Arthur and Ley 2013; Patterson et al. 2014). These observations indicate that inhibitors of the NF- $\kappa \mathrm{B}$ and MAPKs signaling pathways are potential targets for new therapeutic strategies to reduce inflammation-mediated diseases.

Recently, interest has increased in the pharmacological activity of herbal medicines widely used in traditional medicines of East Asia, including Korea, China, and Japan. Numerous studies support the potential clinical benefits of these medicines against difficult to treat diseases. Among them, Fructus sophorae (goegak in Korean), the dried ripe fruit of Styphnolobium japonicum (L.) Schott belonging to the family Fabaceae has been used as an herbal medicine for the treatment of hemorrhoids, constipation, hemostasis, and hyperlipidemia for thousands of years (Liu and Sheu 1989; Gan et al. 2010). Modern pharmacological studies have shown that Fructus sophorae mainly contains flavonoids, isoflavones, and their glycosides as its major active components (Joo et al. 2004, 2005; Kite et al. 2009; Chang et al. 2013; Shi et al. 2013; Zhi et al. 2014). Several studies have revealed that some of Fructus sophorae's components have antiosteoporotic (Joo et al. 2004; Shim et al. 2005), antiviral (Kim et al. 2010), and antioxidant (Joo et al. 2005; Feng et al. 2015) properties. Despite these encouraging studies, little is known about the effects of these components or the mechanisms responsible for their anti-inflammatory activity. As a part of an ongoing screening program to evaluate the anti-inflammatory potentials of new compounds from traditional medicinal resources, this study investigated the anti-inflammatory effects of Fructus sophorae extract (FSE) in RAW 264.7 macrophages activated with LPS and examined whether FSE inhibited inflammatory responses via the suppression of the NF- $\kappa \mathrm{B}$ and MAPKs signaling pathways.

\section{Materials and Methods}

\section{Preparation of FSE}

To prepare FSE, the Fructus sophorae was subjected to reflux extraction with a $60 \%$ ethanol aqueous solution for $2 \mathrm{~h}$. The crude extract was filtered with a $0.45-\mathrm{mM}$ filter to remove insoluble materials, and then it was concentrated under reduced pressure in a rotary evaporator to remove the ethanol. The FSE was dissolved in dimethyl sulfoxide (DMSO, Sigma-Aldrich Chemical Co., St. Louis, MO, USA) to create a $100 \mathrm{mg} / \mathrm{ml}$ FSE stock solution. The stock solution was then diluted with culture medium to the desired concentration prior to use. The final concentration of DMSO never exceeded $0.1 \%$.

\section{Cell culture and LPS treatment}

RAW 264.7 cells, a murine macrophage cell line, were obtained from the American Type Culture Collection (Manassas, VA, USA). The cells were grown in Dulbecco's modified Eagle's medium (DMEM, WelGENE Inc., Daegu, South Korea) containing 10\% fetal bovine serum (WelGENE Inc.), $100 \mathrm{U} / \mathrm{ml}$ penicillin, and $100 \mathrm{mg} / \mathrm{ml}$ streptomycin in an incubator at $37^{\circ} \mathrm{C}, 5 \% \mathrm{CO}_{2}$, and $95 \%$ humidity. To stimulate the cells, the medium was exchanged with fresh DMEM, and LPS (100 ng/ml, Sigma-Aldrich Chemical Co.) was added in the presence or absence of FSE for the indicated periods.

\section{Assessment of cell viability}

The effects of FSE on cell viability were evaluated using a colorimetric 3-[4,5-dimethylthiazol-2-yl]-2,5-diphenyltetrazolium bromide (MTT, Sigma-Aldrich Chemical Co.) assay. The RAW 264.7 cells were seeded at a density of $1 \times 10^{4}$ cells/well into a 96 -well plate, incubated at $37^{\circ} \mathrm{C}$ for $24 \mathrm{~h}$, and then treated with various concentrations of FSE alone or with LPS (500 ng/ml). After $24 \mathrm{~h}$ incubation, MTT solution was added to each well and the plate was incubated for an additional $4 \mathrm{~h}$ at $37^{\circ} \mathrm{C}$. After the MTT incubation, the medium was discarded and DMSO was added to dissolve the formazan dye. Then the optical density was read at $450 \mathrm{~nm}$ with an enzyme-linked immunosorbent assay (ELISA) reader (Molecular Devices, Sunnyvale, CA, USA). 


\section{Measurement of NO production}

The $\mathrm{NO}_{2}{ }^{-}$concentrations in the culture supernatants was measured to assess NO production with the Griess reagent (1\% sulfanilamide, $0.1 \%$ naphthylethylenediamine dihydrochloride, and $2.5 \%$ phosphoric acid, Sigma-Aldrich Chemical Co.). The cells were pretreated with various concentrations of FSE for $1 \mathrm{~h}$ and stimulated with LPS for $24 \mathrm{~h}$. Then $100 \mu \mathrm{l}$ of the Griess reagent was mixed with an equal volume of cell supernatant and incubated at room temperature in the dark for $5 \mathrm{~min}$. The optical density at $540 \mathrm{~nm}$ was measured and the concentration of nitrite was calculated according to the standard curve generated from known concentrations of sodium nitrite (Lee et al. 2014).

\section{$P G E_{2}, I L-6$, and IL-1 $\beta$ immunoassay}

The amounts of $\mathrm{PGE}_{2}$ and proinflammatory cytokines released in the culture medium were measured with mouse PGE $_{2}$, IL-6, and IL-1 $\beta$ ELISA kits (R\&D Systems, Minneapolis, MN, USA) based on the quantitative sandwich enzyme immunosorbent technique. FSE was pretreated for $1 \mathrm{~h}$ before LPS stimulation, and then the cells were incubated with LPS for $24 \mathrm{~h}$. The levels of PGE 2 , IL-6, and IL- $1 \beta$ in the culture media were quantified using ELISA kits according to the manufacturer's instructions. The absorbance was read at a wavelength of $450 \mathrm{~nm}$ with a microplate reader (Hwang et al. 2014).

RNA isolation and reverse transcriptase-polymerase chain reaction ( $R T-P C R)$

Total RNA was isolated using the TRIzol reagent (Invitrogen Life Technologies, Carlsbad, CA, USA) according to the manufacturer's instructions and reverse transcribed using MMLV reverse transcriptase (Promega, Madison, WI, USA) to produce cDNAs. RT-generated cDNAs encoding iNOS, $C O X-2, I L-6$, and $I L-1 \beta$ genes were amplified by PCR with selective primers (Bioneer, Seoul, South Korea). The PCR primers were as follows: mouse iNOS (5'-ATG TCC GAA GCA AAC ATC AC-3' and 5'-TAA TGT CCA GGA AGT AGG TG-3'), COX-2 (5'-CAG CAA ATC CTT GCT GTT CC-3' and 5'-TGG GCA AAG AAT GCA AAC ATC-3'), IL-6 (5'- GGA GGC TTA ATT ACA CAT GTT-3' and 5'-TGA TTT CAA GAT GAA TTG GAT-3'), and $I L-1 \beta$ (5'-ATG GCA ACT GTT CCT GAA CTC AAC T-3' and 5'-TTT CCT TTC TTA GAT ATG GAC AGG AC-3'). After amplification, the $\mathrm{PCR}$ products were electrophoresed in $1 \%$ agarose gels and visualized by ethidium bromide (SigmaAldrich Chemical Co.) staining. In a parallel experiment, glyceraldehyde-3-phosphate dehydrogenase (GAPDH) was used as an internal control.
Western blot analysis

After treatment with FSE in the presence or absence of LPS, the cell pellets were resuspended in lysis buffer (20 mM sucrose, $1 \mathrm{mM}$ ethylenediaminetetraacetic acid, $20 \mu \mathrm{M}$ Tris- $\mathrm{HCl}, \mathrm{pH}$ 7.2, $1 \mathrm{mM}$ dithiothreitol, $10 \mathrm{mM}$ $\mathrm{KCl}, 1.5 \mathrm{mM} \mathrm{MgCl}$, and $5 \mu \mathrm{g} / \mathrm{ml}$ aprotinin). The cell debris was discarded following centrifugation at 13,000 $\times g$ for $15 \mathrm{~min}$. Then the protein concentration was determined using the Bio-Rad kit (Bio-Rad Laboratories, Hercules, CA, USA). In a parallel experiment, nuclear and cytosolic proteins were prepared with nuclear extraction reagents (Pierce Biotechnology, Rockford, IL, USA) according to the manufacturer's protocol. Equal amounts of protein $(20 \sim 30 \mu \mathrm{g})$ from each sample were separated by $10 \%$ sodium dodecyl sulfate (SDS)-polyacrylamide gel electrophoresis and transferred onto nitrocellulose membranes (Schleicher \& Schuell, Keene, NH, USA). The nonspecific sites were blocked by incubating the membranes in $5 \%(\mathrm{w} / \mathrm{v})$ nonfat milk powder in Tris-buffered saline containing $0.05 \%(\mathrm{v} / \mathrm{v})$ Tween-20 (TBS-T) for $1 \mathrm{~h}$ at room temperature. Then the reactive bands were visualized with horseradish peroxidase-coupled secondary antibody via an enhanced chemiluminescence (ECL) detection system (Amersham Co., Arlington Heights, IL, USA) according to the manufacturer's procedures. Various primary and secondary antibodies for Western blot analysis were purchased from Cell Signaling Technology, Inc. (Boston, MA, USA) and Santa Cruz Biotechnology (Santa Cruz, CA, USA).

\section{Immunofluorescent staining for NF- $\kappa B$ p 65}

The RAW 264.7 cells were seeded onto glass coverslips in 6-well plates for $24 \mathrm{~h}$. The cells were pretreated with or without FSE for $1 \mathrm{~h}$ and then treated with LPS for $30 \mathrm{~min}$. After the treatment, the cells were rinsed twice with phosphate-buffered saline (PBS) and fixed with 3.7\% paraformaldehyde in PBS for $10 \mathrm{~min}$ at $4^{\circ} \mathrm{C}$. Then the cells were incubated with $0.4 \%$ Triton $\mathrm{X}-100$ for $10 \mathrm{~min}$ followed by blocking with $5 \%$ bovine serum albumin for $1 \mathrm{~h}$. After the blocking, the cells were probed with rabbit anti-p65 NF- $\kappa$ B antibody (Santa Cruz Biotechnology) overnight at $4^{\circ} \mathrm{C}$. Then the cells were incubated with fluorescein isothiocyanate-conjugated donkey anti-rabbit IgG (Jackson ImmunoResearch Laboratories Inc., West Grove, PA, USA) for $2 \mathrm{~h}$ at room temperature (Kim et al. 2014). After the incubation, the cells were washed with PBS, and the cell nuclei were counterstained with $1 \mathrm{mg} / \mathrm{ml}$ 4,6-diamidino2-phenylindole (DAPI) solution for $15 \mathrm{~min}$ in the dark and then mounted with mounting medium. The NF-kB p65 subunit was observed with a fluorescence microscope (Carl Zeiss, Oberkochen, Germany). 


\section{Statistical analysis}

Data from at least three independent experiments were expressed as the mean \pm standard deviation. Statistical comparisons between different groups were performed using one-way ANOVA followed by the Student's $t$-test after comparing each treated group to the negative control. Values of $p$ less than 0.01 were considered statistically significant.

\section{Results}

FSE inhibits LPS-induced production of $\mathrm{NO}$ and $P G E_{2}$ in RAW 264.7 macrophages

The presence of $\mathrm{NO}$ and $\mathrm{PGE}_{2}$ is widely used as indicators of microphage activation among many inflammatory
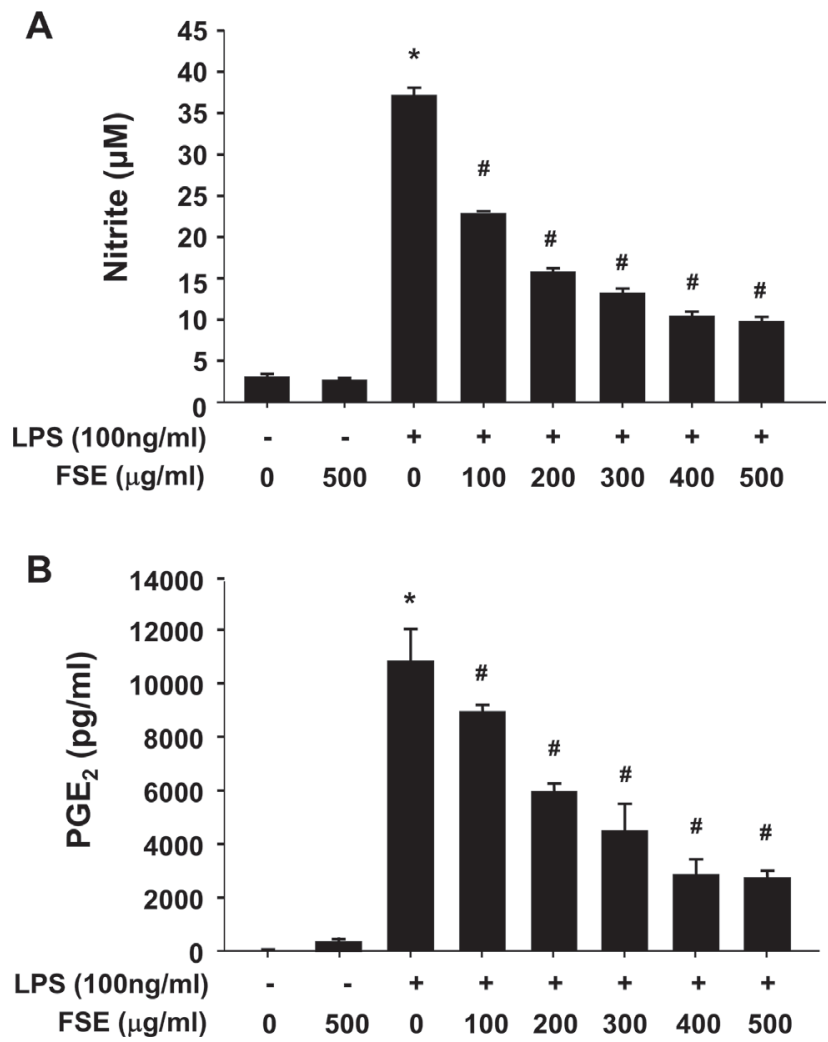

Figure 1. Fructus sophorae extract (FSE) inhibition of NO and prostaglandin $\mathrm{E}_{2}\left(\mathrm{PGE}_{2}\right)$ production in lipopolysaccharide (LPS)-stimulated RAW 264.7 macrophages. RAW 264.7 cells were pretreated with various concentrations of FSE for $1 \mathrm{~h}$ prior to incubation with 100 $\mathrm{ng} / \mathrm{ml}$ LPS for $24 \mathrm{~h}$. A. Nitrite content was measured with the Griess reaction. B. $\mathrm{PGE}_{2}$ concentration was measured in culture media with a commercial ELISA kit. Each value indicates the mean \pm S.D. and is representative of the results obtained from three independent experiments. Statistical significance was determined by one-way ANOVA $\left({ }^{*} p<0.05 v\right.$ s. untreated control; ${ }^{\#} p<0.05 v s$. LPS-treated group). mediators (Joubert and Malan 2011; Norberg et al. 2013). iNOS and COX-2 were expressed in activated macrophages, mediating the synthesis of $\mathrm{NO}$ and $\mathrm{PGE}_{2}$ released into the culture medium. Therefore, the RAW 264.7 cells were challenged with LPS in the presence or absence of FSE, and the levels of $\mathrm{NO}$ and $\mathrm{PGE}_{2}$ were measured by Griess reagent and ELISA, respectively. As presented in Figure 1, pretreatment with FSE concentration-dependently suppressed NO and $\mathrm{PGE}_{2}$ secretion with statistical significance. The inhibitory effect of FSE on $\mathrm{NO}$ and $\mathrm{PGE}_{2}$ production was also investigated in relation to the modulation of iNOS and COX-2 enzyme levels. Figure 2A demonstrates that FSE strongly suppressed the protein expression of iNOS and COX-2 compared with the LPS alone-treated group. Furthermore, FSE markedly repressed iNOS and COX-2 mRNA expression in LPS-stimulated RAW 264.7 cells (Fig. 2B), suggesting that the FSE-mediated inhibition of $\mathrm{NO}$ and $\mathrm{PGE}_{2}$ production is associated with the transcriptional downregulation of the iNOS and COX-2 genes.

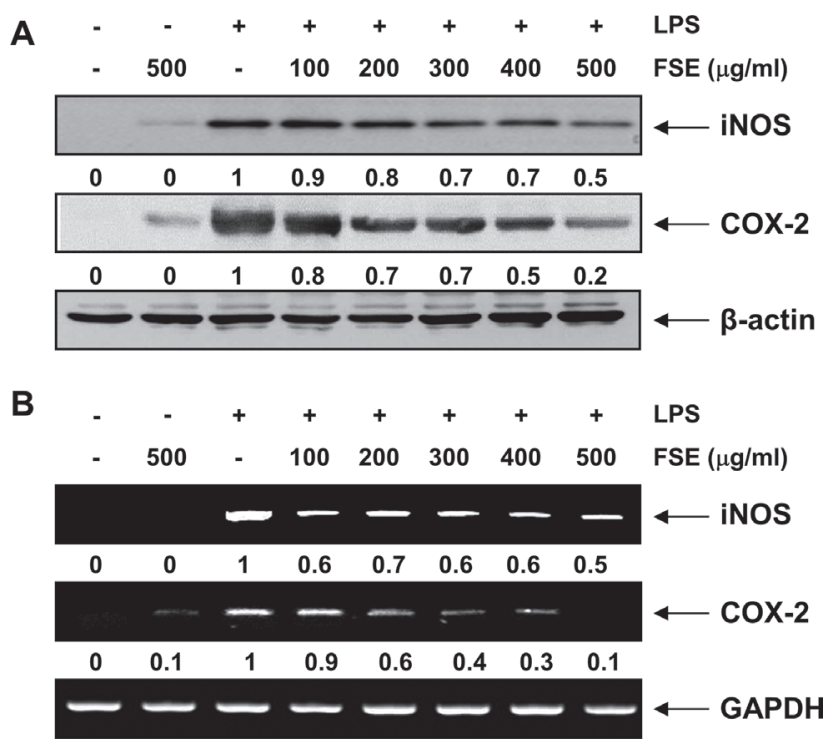

Figure 2. FSE inhibition of inducible NO synthase (iNOS) and cyclooxygenase-2 (COX-2) expression in LPS-stimulated RAW 264.7 macrophages. RAW 264.7 cells were pretreated with the indicated concentrations of FSE for $1 \mathrm{~h}$ prior to incubation with $100 \mathrm{ng} / \mathrm{ml}$ LPS. A. After treatment for $24 \mathrm{~h}$, cell lysates were then prepared and Western blotting was performed using antibodies specific for murine iNOS and COX-2. B. Following $6 \mathrm{~h}$ treatment, total RNA was isolated, and RT-PCR was performed using iNOS and COX-2 primers. Actin and GAPDH were used as the internal controls for the Western blot assay and RT-PCR, respectively. The relative ratios of expression in the results of the Western blotting and RT-PCR were presented at the bottom of each of the results as relative values of the $\beta$-actin and GAPDH expression, respectively. For more abbreviations see Fig. 1. 
FSE inhibits the release of $I L-6$ and $I L-1 \beta$ in LPS-stimulated RAW 264.7 cells

The proinflammatory cytokines IL- 6 and IL- $1 \beta$ are produced in response to inflammatory stimuli and, in turn, can contribute to inflammation (McCarty and Frishman 2014; Rath et al. 2015); thus, they are regarded as targets for inhibiting inflammatory processes. To confirm the effect of FSE on the production of proinflammatory cytokines, the concentrations of IL- 6 and IL- $1 \beta$ in the culture medium were measured by ELISA. Consistent with the $\mathrm{NO}$ and $\mathrm{PGE}_{2}$ results, FSE inhibited IL- 6 and IL- $1 \beta$ cytokine production concentration-dependently (Fig. 3). Moreover, FSE treatment clearly inhibited the LPS-induced expression of IL-6
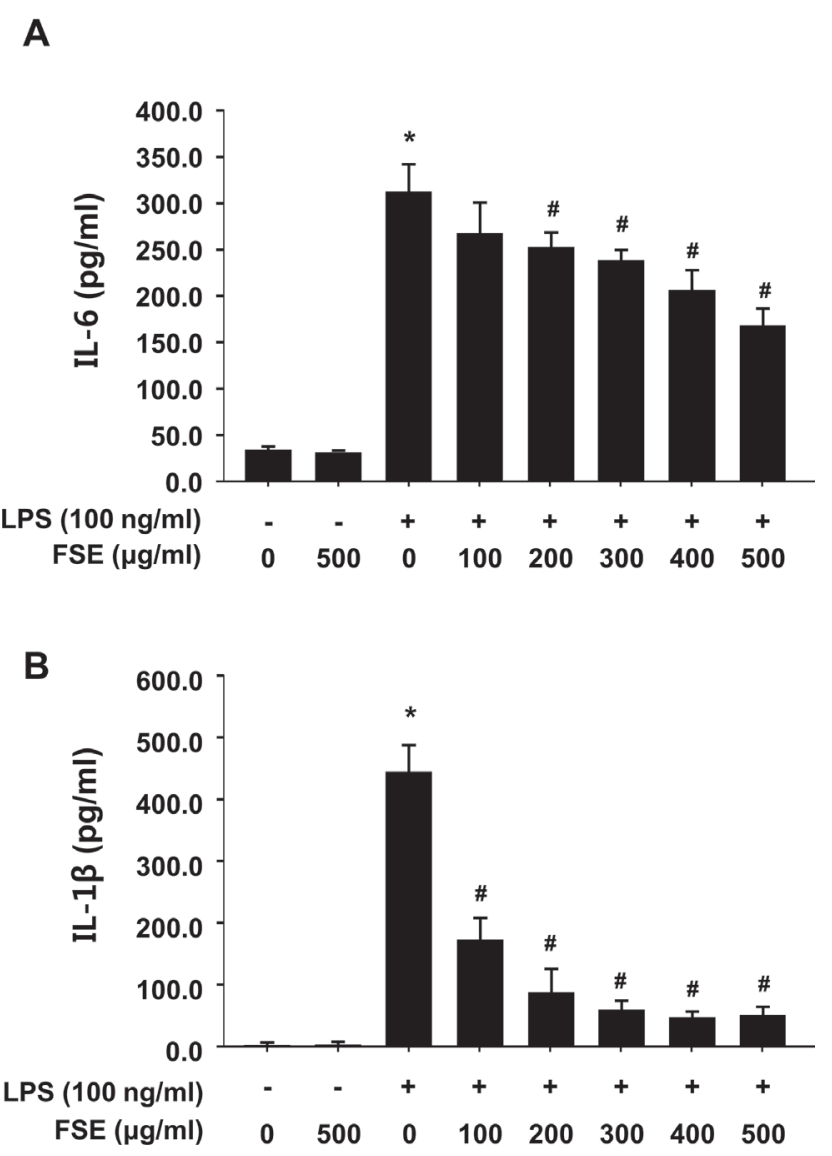

Figure 3. FSE inhibition of IL- 6 and IL-1 $\beta$ production in LPS-stimulated RAW 264.7 macrophages. RAW 264.7 cells were pretreated with various concentrations of FSE for $1 \mathrm{~h}$ prior to $100 \mathrm{ng} / \mathrm{ml}$ LPS treatment. After incubation for $24 \mathrm{~h}$, levels of IL-6 (A) and IL-1 $\beta$ (B) present in the supernatants were measured using commercial ELISA kits. Each value indicates the mean \pm S.D. and is representative of the results obtained from three independent experiments. Statistical significance was determined by one-way ANOVA $\left({ }^{*} p<0.05 v s\right.$. untreated control; ${ }^{\#} p<0.05$ vs. LPS-treated group). For abbreviations see Fig. 1. and IL- $1 \beta$ protein and mRNA compared with the LPS alone-treated group (Fig. 4). These results showed that FSE was able to inhibit the expression of IL- 6 and IL- $1 \beta$ at the transcriptional levels, thus, reducing the production of IL-6 and IL-1 $\beta$ in LPS-stimulated RAW 264.7 cells.

\section{FSE inhibits NF- $\kappa B$ pathway activation in RAW 264.7 macrophages after LPS stimulation}

$\mathrm{NF}-\kappa \mathrm{B}$ plays a pivotal role in the regulation of iNOS, COX-2, and inflammatory cytokine expression. As such, $\mathrm{NF}-\kappa \mathrm{B}$ is a good target for treating inflammatory diseases (Ivashkiv 2011; Gasparini and Feldmann 2012). Therefore, this study investigated whether FSE suppressed the nuclear translocation of NF- $\kappa$ B by Western blotting analysis after the cells were pretreated with the indicated concentrations of FSE for $1 \mathrm{~h}$ and stimulated with LPS for $30 \mathrm{~min}$. After treatment with LPS alone, the levels of p65, a component of the NF- $\kappa \mathrm{B}$ heterodimer, were markedly increased, and FSE effectively blocked the LPS-induced accumulation of NF- $\kappa$ B p65 in the nucleus (Fig. 5A). These results were

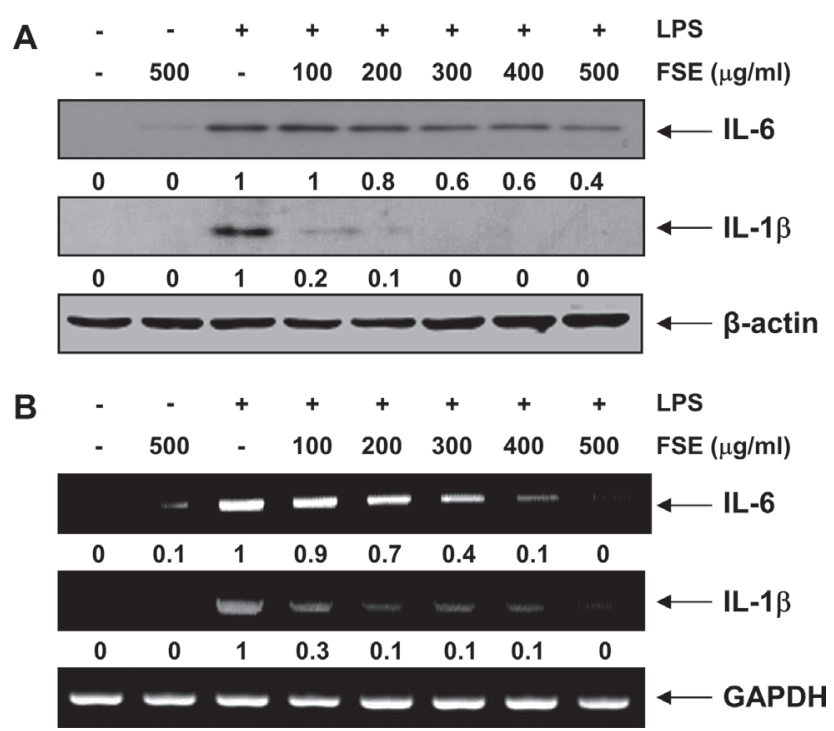

Figure 4. FSE inhibition of IL- 6 and IL- $1 \beta$ expression in LPS-stimulated RAW 264.7 macrophages. RAW 264.7 cells were pretreated with the indicated concentrations of FSE for $1 \mathrm{~h}$ prior to incubation with $100 \mathrm{ng} / \mathrm{ml}$ LPS. A. After treatment for $24 \mathrm{~h}$, cell lysates were then prepared and Western blotting was performed using antibodies specific for murine IL- 6 and IL-1 $\beta$. B. After $6 \mathrm{~h}$ treatment, total RNA was isolated, and RT-PCR was performed using IL-6 and IL- $1 \beta$ primers. Actin and GAPDH were used as the internal controls for the Western blot assay and RT-PCR, respectively. The relative ratios of expression in the results of the Western blotting and RT-PCR were presented at the bottom of each of the results as relative values of the $\beta$-actin and GAPDH expression, respectively. For abbreviations see Fig. 1. 
confirmed by NF- $\mathrm{BB}$ and DAPI costaining in LPS-treated RAW 264.7 cells and FSE markedly preventing the nuclear translocation of p65 (Fig. 5B). The findings indicate that the inactivation of the NF- $\kappa \mathrm{B}$ signaling pathway was involved in the anti-inflammatory effect of FSE in LPS-stimulated RAW 264.7 cells.

A

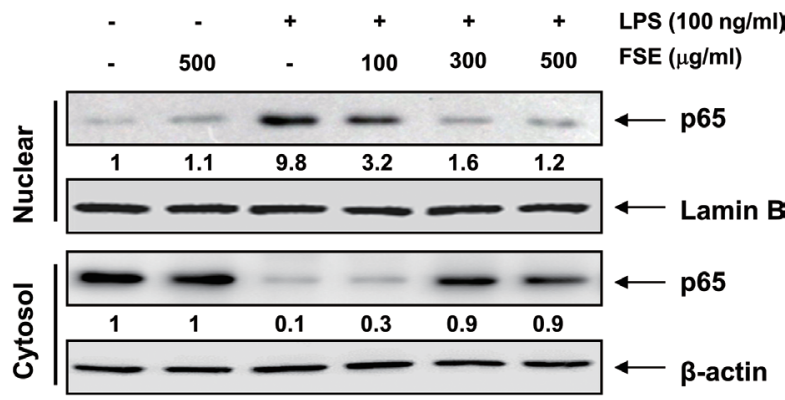

B

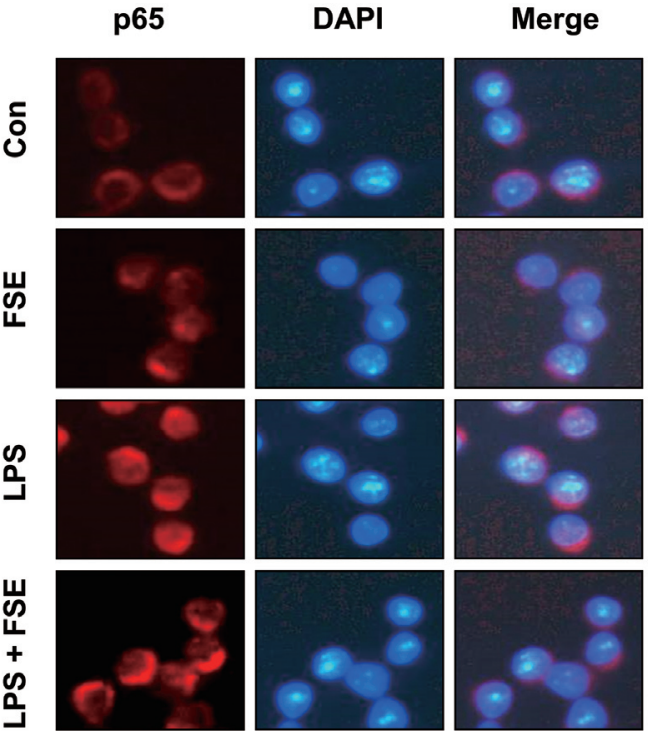

Figure 5. FSE suppression of LPS-induced NF- $\kappa B$ nuclear translocation in RAW 264.7 macrophages. Cells were treated with the indicated concentrations of FSE for $1 \mathrm{~h}$ before $100 \mathrm{ng} / \mathrm{ml}$ LPS treatment for $30 \mathrm{~min}$. A. Nuclear and cytosolic proteins were subjected to $10 \%$ SDS-polyacrylamide gel electrophoresis followed by Western blotting with the anti-NF- $\kappa$ B p65 antibody. Lamin B and actin were used as the internal controls for the nuclear and cytosolic fractions, respectively. The relative ratios of expression in the results of the Western blotting were presented at the bottom of each of the results as relative values of the lamin $\mathrm{B}$ and $\beta$-actin expression, respectively. B. Cells were pretreated with $500 \mu \mathrm{g} / \mathrm{ml}$ of FSE for $1 \mathrm{~h}$ prior to stimulation with $100 \mathrm{ng} / \mathrm{ml}$ LPS for $30 \mathrm{~min}$. Localization of NF- $\kappa B$ p 65 was visualized with a fluorescence microscope after immunofluorescence staining with anti-NF- $\kappa B$ p 65 antibody (green). Cells were also stained with DAPI for visualization of the nuclei (blue). For abbreviations see Fig. 1.
FSE suppresses LPS-induced phosphorylation of MAPKs in RAW 264.7 macrophages

The activation of the MAPKs pathways is also crucial for LPS-stimulated NF- $\kappa \mathrm{B}$ activation and the subsequent activation of inflammatory mediators (Broom et al. 2009; Arthur and Ley 2013). To investigate whether the suppression of inflammatory reactions by FSE was mediated through the MAPKs pathway, the effect of FSE on the LPSinduced phosphorylation of ERK, JNK, and p38 MAPK was assessed. As shown in Fig. 6, ERK, JNK, and p38 MAPK phosphorylation was increased after treatment with LPS for $30 \mathrm{~min}$. However, pretreatment with FSE significantly suppressed the LPS-induced phosphorylation of ERK and JNK but not p38 MAPK. These results indicate that the anti-inflammatory effect of FSE might be mediated via the blockage of ERK and JNK phosphorylation but independent of the activation of p38 MAPK.

Effects of FSE on cell viability in LPS-stimulated RAW 264.7 macrophages

The effects of FSE on the viability of RAW 264.7 cells were determined by a colorimetric MTT assay after incubation with or without $100 \mathrm{ng} / \mathrm{ml}$ LPS in the presence or absence of FSE for $24 \mathrm{~h}$. The data were expressed as the percentage of cell viability compared to those of the

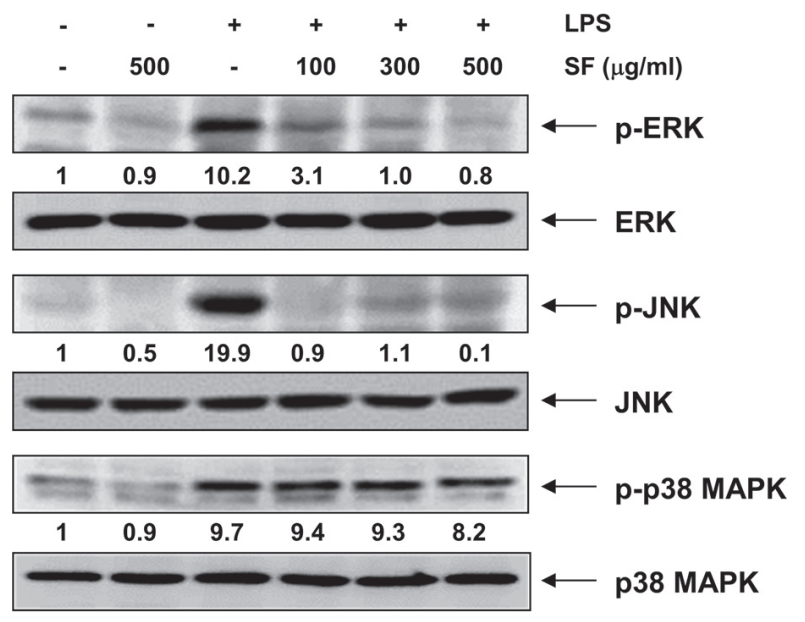

Figure 6. Effects of FSE on LPS-induced phosphorylation of MAPKs in RAW 264.7 macrophages. RAW 264.7 cells were pretreated with various concentrations of FSE for $1 \mathrm{~h}$ prior to exposure to $100 \mathrm{ng} / \mathrm{ml} \mathrm{LPS} \mathrm{for} 30 \mathrm{~min}$, and total proteins were isolated. The proteins were subjected to SDS-polyacrylamide gels followed by Western blot analysis with the indicated antibodies and an ECL detection system. The numbers represent the average densitometric analyses of phosphor-MAPKs as compared with total MAPKs expression. For abbreviations see Fig. 1. 


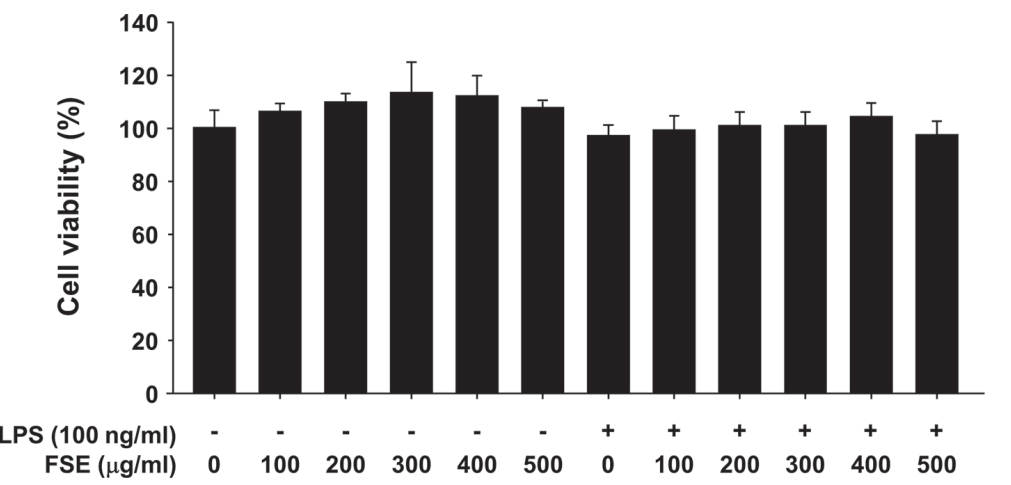

Figure 7. Effects of FSE and LPS on cell viability of RAW 264.7 macrophages. Cells were treated with the indicated concentrations of FSE alone or pretreated with FSE for $1 \mathrm{~h}$ before $100 \mathrm{ng} / \mathrm{ml}$ LPS treatment for $24 \mathrm{~h}$. Cell viability was assessed using the MTT reduction assay, and the results are expressed as the percentage of surviving cells over control cells (no addition of FSE or LPS). Each value indicates the mean \pm S.D. and is representative of the results obtained from three independent experiments. For abbreviations see Fig. 1. control. The concentrations (100 to $500 \mu \mathrm{g} / \mathrm{ml}$ ) of FSE used for the inhibition of proinflammatory mediators and cytokines did not show any cytotoxicity (Fig. 7), confirming that the anti-inflammatory potential of FSE in LPS-stimulated RAW 264.7 cells was not due to a cytotoxic action of FSE.

\section{Discussion}

The overproduction of proinflammatory mediators and cytokines by activated macrophages causes various inflammatory diseases (Tsatsanis et al. 2006; Keystone and Ware 2010; Lane and Lachmann 2011; Kalinski 2012; Rossi et al. 2015). Therefore, identifying new agents capable of lowering proinflammatory reactions are essential for the alleviation of a number of inflammation-related disorders attributed to macrophage activation. In the present study, the production of $\mathrm{NO}$ and $\mathrm{PGE}_{2}$ in response to LPS was markedly increased; however, the application of FSE inhibited the LPS-induced production of $\mathrm{NO}$ and $\mathrm{PGE}_{2}$ in a concentration-dependent manner (Fig. 1). The results from the RT-PCR and Western blot analysis showed that pretreatment with FSE reduced the iNOS and COX-2 mRNA levels with correlated reductions in the corresponding proteins levels in a concentrationdependent manner (Fig. 2). In addition, FSE was highly effective at IL- 6 and IL- $1 \beta$ production inhibition, which was associated with the reduction of IL- 6 and IL- $1 \beta$ mRNA and protein expression in LPS-treated RAW 264.7 cells (Figs. 3 and 4 ). The data indicates that FSE reduces the mRNA levels of iNOS, COX-2, IL-6, and IL-1 $\beta$, leading to decreased protein levels and, consequently, reduced quantities of $\mathrm{NO}$, PGE $_{2}$, IL-6, and IL-1 $\beta$.

The accumulated data demonstrated that the transcription of a variety of proinflammatory mediators and cytokines from activated macrophages are mainly regulated by certain transcription factors. Among these factors, the $\mathrm{NF}-\kappa \mathrm{B}$ transcription factor family is the critical mediator of inflammatory processes; thus, the inactivation of NF- $\mathrm{BB}$ in the immune system is a major therapeutic target for the downregulation of inflammatory responses (Ivashkiv 2011; Gasparini and Feldmann 2012). In addition to the NF- $\kappa$ B signaling pathway, the MAPKs appear to play key roles in inflammatory processes because the phosphorylation of MAPKs can stimulate the activation of NF- $\kappa B$ (Broom et al. 2009; Arthur and Ley 2013; Patterson et al. 2014). Therefore, the MAPKs signaling cascade is also an attractive therapeutic target for the development of treatments for inflammatory disorders.

In this study, Western blotting revealed that FSE was able to inhibit the LPS-evoked nuclear translocation of NF- $\kappa$ B p65 (Fig. 5). To investigate whether the inhibition of NF- $\kappa \mathrm{B}$ activation by FSE is associated with the MAPKs pathways, the LPS-induced phosphorylation of ERK, JNK, and p38 MAPK was assessed in RAW 264.7 cells. The immunoblotting results revealed that the phosphorylation of ERK and JNK in response to LPS is abolished by FSE pretreatment (Fig. 6). However, FSE failed to inhibit LPS-induced p38 MAPK phosphorylation, indicating that the anti-inflammatory responses by FSE may be independent of the p38 MAPK signaling pathway. These results suggest that FSE blocked the activation of NF- $\kappa \mathrm{B}$ through changes in the phosphorylation of ERK and JNK. Thus, deficiencies in the phosphorylation of these kinases could decrease the expression levels of inflammation-related genes.

In summary, our findings show that FSE effectively inhibits the LPS-induced production of proinflammatory mediators and cytokines in RAW 264.7 macrophages without causing cytotoxicity. A possible mechanism for this effect involves FSE's ability to activate a signaling cascade resulting in the repression of NF- $\mathrm{KB}, \mathrm{ERK}$, and JNK activation in LPS-challenged macrophages. Although further investigation is needed to clarify the precise mechanisms by which FSE inhibits NF- $\kappa$ B activation and to identify the responsible biologically active compounds, FSE should be considered a potential therapeutic agent for the treatment of inflammation-related disease. 
Conflict of interest. The author has no conflict of interest to declare.

Acknowledgements. This work was supported by the High Valueadded Food Technology Development Program (314043-3), Ministry of Agriculture, Food and Rural Affairs, and the project titled 'Omics based on fishery disease control technology development and industrialization', funded by the Ministry of Oceans and Fisheries, Korea (20150242).

\section{References}

Arthur J. S., Ley S. C. (2013): Mitogen-activated protein kinases in innate immunity. Nat. Rev. Immunol. 13, 679-692 http://dx.doi.org/10.1038/nri3495

Broom O. J., Widjaya B., Troelsen J., Olsen J., Nielsen O. H. (2009): Mitogen activated protein kinases: a role in inflammatory bowel disease? Clin. Exp. Immunol. 158, 272-280 http://dx.doi.org/10.1111/j.1365-2249.2009.04033.x

Chang L., Zhang X. X., Ren Y. P., Cao L., Zhi X. R., Zhang L. T. (2013): Simultaneous quantification of six major flavonoids from Fructus sophorae by LC-ESI-MS/MS and statistical analysis. Indian J. Pharm. Sci. 75, 330-338 http://dx.doi.org/10.4103/0250-474X.117437

Drexler S. K., Foxwell B. M. (2010): The role of toll-like receptors in chronic inflammation. Int. J. Biochem. Cell. Biol. 42, 506-518 http://dx.doi.org/10.1016/j.biocel.2009.10.009

Feng C., Jin S., Xia X. X., Guan Y., Luo M., Zu Y. G., Fu Y. J. (2015): Effective bioconversion of sophoricoside to genistein from Fructus sophorae using immobilized Aspergillus niger and yeast. World J. Microbiol. Biotechnol. 31, 187-197 http://dx.doi.org/10.1007/s11274-014-1777-y

Gan T., Liu Y. D., Wang Y., Yang J. (2010): Traditional Chinese medicine herbs for stopping bleeding from haemorrhoids. Cochrane Database Syst. Rev. 6, CD006791 http://dx.doi.org/10.1002/14651858.cd006791.pub2

Gasparini C., Feldmann M. (2012): NF- $\kappa B$ as a target for modulating inflammatory responses. Curr. Pharm. Des. 18, 5735-5745 http://dx.doi.org/10.2174/138161212803530763

Hayden M. S., Ghosh S. (2014): Regulation of NF- $\kappa$ B by TNF family cytokines. Semin. Immunol. 26, 253-266 http://dx.doi.org/10.1016/j.smim.2014.05.004

Hwang Y. J., Song J., Kim H. R., Hwang K. A. (2014): Oleanolic acid regulates NF- $\kappa \mathrm{B}$ signaling by suppressing MafK expression in RAW 264.7 cells. BMB Rep. 47, 524-529 http://dx.doi.org/10.5483/BMBRep.2014.47.9.149

Ivashkiv L. B. (2011): Inflammatory signaling in macrophages: transitions from acute to tolerant and alternative activation states. Eur. J. Immunol. 41, 2477-24781 http://dx.doi.org/10.1002/eji.201141783

Joo S. S., Kwon S. H., Hwang K. W., Lee D. I. (2005): Improvement of menopausal signs by isoflavones derived from Sophorae fructus in ovariectomized female rats and the antioxidant potentials in BV2 cells. Arch. Pharm. Res. 28, 566-572 http://dx.doi.org/10.1007/BF02977760
Joo S. S., Won T. J., Kang H. C., Lee D. I. (2004): Isoflavones extracted from Sophorae fructus upregulate IGF-I and TGF-beta and inhibit osteoclastogenesis in rat bone marrow cells. Arch. Pharm. Res. 27, 99-105 http://dx.doi.org/10.1007/BF02980054

Joubert J., Malan S. F. (2011): Novel nitric oxide synthase inhibitors: a patent review. Expert. Opin. Ther. Pat. 21, 537-560

Kalinski P. (2012): Regulation of immune responses by prostaglandin E2. J. Immunol. 188, 21-18 http://dx.doi.org/10.4049/jimmunol.1101029

Keystone E. C., Ware C. F. (2010): Tumor necrosis factor and anti-tumor necrosis factor therapies. J. Rheumatol. Suppl. 85, 27-39 http://dx.doi.org/10.3899/jrheum.091463

Kim B. H., Oh I., Kim J. H., Jeon J. E., Jeon B., Shin J., Kim T. Y. (2014): Anti-inflammatory activity of compounds isolated from Astragalus sinicus L. in cytokine-induced keratinocytes and skin. Exp. Mol. Med. 46, e87 http://dx.doi.org/10.1038/emm.2013.157

Kim H. Y., Eo E. Y., Park H., Kim Y. C., Park S., Shin H. J., Kim K. (2010): Medicinal herbal extracts of Sophorae radix, Acanthopanacis cortex, Sanguisorbae radix and Torilis fructus inhibit coronavirus replication in vitro. Antivir. Ther. 15, 697-709 http://dx.doi.org/10.3851/IMP1615

Kite G. C., Veitch N. C., Boalch M. E., Lewis G. P., Leon C. J., Simmonds M. S. (2009): Flavonol tetraglycosides from fruits of Styphnolobium japonicum (Leguminosae) and the authentication of Fructus Sophorae and Flos Sophorae. Phytochemistry 70, 785-794 http://dx.doi.org/10.1016/j.phytochem.2009.04.003

Kotas M. E., Medzhitov R. (2015): Homeostasis, inflammation, and disease susceptibility. Cell 160, 816-827 http://dx.doi.org/10.1016/j.cell.2015.02.010

Lan W., Petznick A., Heryati S., Rifada M., Tong L. (2012): Nuclear Factor- $\mathrm{kB}$ : central regulator in ocular surface inflammation and diseases. Ocul. Surf. 10, 137-148 http://dx.doi.org/10.1016/j.jtos.2012.04.001

Lane T., Lachmann H. J. (2011): The emerging role of interleukin$1 \beta$ in autoinflammatory diseases. Curr. Allergy Asthma Rep. $11,361-368$ http://dx.doi.org/10.1007/s11882-011-0207-6

Laveti D., Kumar M., Hemalatha R., Sistla R., Naidu V. G., Talla V., Verma V., Kaur N., Nagpal R. (2013): Anti-inflammatory treatments for chronic diseases: a review. Inflamm. Allergy Drug Targets 12, 349-361 http://dx.doi.org/10.2174/18715281113129990053

Lee J. Y., Lee B. H., Lee J. Y. (2015): Gambogic acid disrupts toll-like receptor 4 activation by blocking lipopolysaccharides binding to myeloid differentiation factor 2. Toxicol. Res. 31, 11-16 http://dx.doi.org/10.5487/TR.2015.31.1.011

Lee K. P., Sudjarwo G. W., Kim J. S., Dirgantara S., Maeng W. J., Hong H. (2014): The anti-inflammatory effect of Indonesian Areca catechu leaf extract in vitro and in vivo. Nutr. Res. Pract. 8, 267-271 http://dx.doi.org/10.4162/nrp.2014.8.3.267

Leon C. G., Tory R., Jia J., Sivak O., Wasan K. M. (2008): Discovery and development of toll-like receptor 4 (TLR4) antagonists: a new paradigm for treating sepsis and other diseases. Pharm. Res. 25, 1751-1761 http://dx.doi.org/10.1007/s11095-008-9571-x 
Liu I. M., Sheu S. J. (1989): Analysis and processing of Chinese herbal drugs. VIII: The study of sophorae floe. Am. J. Chin. Med. 17, 179-187 http://dx.doi.org/10.1142/S0192415X89000279

Lucas K., Maes M. (2013): Role of the Toll Like receptor (TLR) radical cycle in chronic inflammation: possible treatments targeting the TLR4 pathway. Mol. Neurobiol. 48, 190-204 http://dx.doi.org/10.1007/s12035-013-8425-7

McCarty S., Frishman W. (2014): Interleukin 1ß: a proinflammatory target for preventing atherosclerotic heart disease. Cardiol. Rev. 22, 176-181 http://dx.doi.org/10.1097/CRD.0000000000000022

Norberg J. K., Sells E., Chang H. H., Alla S. R., Zhang S., Meuillet E. J. (2013): Targeting inflammation: multiple innovative ways to reduce prostaglandin E2. Pharm. Pat. Anal. 2, 265-288 http://dx.doi.org/10.4155/ppa.12.90

Patterson H., Nibbs R., McInnes I., Siebert S. (2014): Protein kinase inhibitors in the treatment of inflammatory and autoimmune diseases. Clin. Exp. Immunol. 176, 1-10 http://dx.doi.org/10.1111/cei.12248

Rath T., Billmeier U., Waldner M. J., Atreya R., Neurath M. F. (2015): From physiology to disease and targeted therapy: interleukin- 6 in inflammation and inflammation-associated carcinogenesis. Arch. Toxicol. 89, 541-554 http://dx.doi.org/10.1007/s00204-015-1461-5

Rossi J. F., Lu Z. Y., Jourdan M., Klein B. (2015): Interleukin-6 as a therapeutic target. Clin. Cancer Res. 21, 1248-1257 http://dx.doi.org/10.1158/1078-0432.CCR-14-2291
Shi Q., Sui L. Z., Lu Y. Q. (2013): Research on flavonoids contents in Fructus sophorae with capillary zone electrophoresis. Pak. J. Pharm. Sci. 26, 1131-1136

Shim J. G., Yeom S. H., Kim H. J., Choi Y. W., Lee D. I., Song K. Y., Kwon S. H., Lee M. W. (2005): Bone loss preventing effect of Sophorae Fructus on ovariectomized rats. Arch. Pharm. Res. 28, $106-110$ http://dx.doi.org/10.1007/BF02975144

Tsatsanis C., Androulidaki A., Venihaki M., Margioris A. N. (2006): Signalling networks regulating cyclooxygenase-2. Int. J. Biochem. Cell. Biol. 38, 1654-1661 http://dx.doi.org/10.1016/j.biocel.2006.03.021

Verstrepen L., Adib-Conquy M., Kreike M., Carpentier I., Adrie C., Cavaillon J. M., Beyaert R. (2008): Expression of the NFkappaB inhibitor ABIN-3 in response to TNF and toll-like receptor 4 stimulation is itself regulated by NF-kappaB. J. Cell. Mol. Med. 12, 316-329 http://dx.doi.org/10.1111/j.1582-4934.2007.00187.x

Zhi X. R., Zhang Z. Y., Jia P. P., Zhang X. X., Yuan L., Sheng N., Zhang L. T. (2015): Qualitative and quantitative determination of 15 main active constituents in Fructus Sophorae pill by liquid chromatography tandem mass spectrometry. Pharmacogn. Mag. 11, 196-207 http://dx.doi.org/10.4103/0973-1296.149739

Received: August 5, 2015

Final version accepted: October 19, 2015

First published online: April 5, 2016 